\title{
FEMINISATION OF DENTISTRY IN BRAZIL FROM THE PERSPECTIVE OF A MOOC- TYPE DISTANCE COURSE - A SHORT REPORT
}

\author{
Deise Garrido MSc ${ }^{1,2,3}$, Camila Maldonado Huanca MSc ${ }^{1,2,3}$, Ana Emilia Oliveira PhD ${ }^{2,4,5}$, Maria Celeste \\ Morita PhD ${ }^{3,6}$, Ana Estela Haddad PhD ${ }^{1,2,3}$ \\ ${ }^{1}$ Department of Orthodontics and Paediatric Dentistry, School of Dentistry of the University of São Paulo, São Paulo, São \\ Paulo, Brazil \\ ${ }^{2}$ FOUSP-SAITE Telehealth Centre, School of Dentistry of the University of São Paulo, São Paulo, São Paulo, Brazil \\ ${ }^{3}$ FOUSP-ABENO Station of the Human Health Resources Observatory Network, Brazilian Ministry of Health, Panamerican \\ Health Organization \\ ${ }^{4}$ School of Dentistry, Federal University of Maranhão, São Luis, Maranhão, Brazil \\ ${ }^{5}$ Brazilian Healthcare System's Open University of Brazil, Federal University of Maranhão, São Luis, Maranhão, Brazil \\ ${ }^{6}$ School of Dentistry of the Londrina State University, Londrina, Paraná, Brazil
}

\begin{abstract}
The Brazilian public healthcare system (SUS - Brazilian Healthcare System) provides free dental care, covering almost half of the Brazilian population. Providing continuing education to thousands of professionals is a difficult and expensive task given the country's large size. SUS' Open University in partnership with public universities provides ongoing education to thousands of healthcare professionals using technological resources for distance learning. A distance learning course, in the MOOC (Massive Open Online Course) modality, was developed to provide continuing medical education for dental surgeons to assist patients with chronic diseases. The course is free and has registered 13,089 participants. Aim: The purpose of this study is to present the profile of the MOOC course participants. Methods: Secondary data were obtained from Federal Council of Dentistry, the National Registry of Health Facilities, the National Institute for Educational Studies and Research Anísio Teixeira and the Registry of Higher Education Institutions and Courses (e-MEC). Data of the MOOC course were collected in the Arouca Platform. Results: Dentists in Brazil are predominantly female. However, in some specialties there are more men than women. The majority of participants on the course were female $73.5 \%$ and in the age group of 21-40 years. Conclusion: This phenomenon is similar to other countries, and needs to be better investigated in Brazil, so that public policies of continuing education of healthcare professionals by means of distance learning, may take the profession's feminisation into consideration.

Keywords: women; distance learning; dentistry; continuing dental education; MOOC; Brazil

Garrido D, et al. JISfTeH 2019;7:e6(1-4).

DOI: https://doi.org/10.29086/JISfTeH.7.e6

Copyright:@ The Authors 2018

Open access, published under Creative Commons Attribution 4.0 BY International Licence
\end{abstract}

\section{Introduction}

The Brazilian public healthcare system (SUS - Brazilian Healthcare System) is one of the few public systems in the world which provides free dental care to the population. In 2018 there were 27,661 oral health teams, providing coverage to $41.8 \%$ of the Brazilian population estimated at 209,090,169 million inhabitants. ${ }^{1}$ One of the problems faced by SUS is to provide continuing education through on-site courses for so many professionals, in a country as large as Brazil. This can be achieved by incorporating currently available technological resources and providing technology enabled distance education. In 2010 the Brazilian Ministry of
Health created the SUS' Open University (UNA-SUS). ${ }^{2}$ In partnership with public Brazilian universities, UNA-SUS provides continuing education to qualifies thousands of healthcare professionals throughout the country by means of distance courses. ${ }^{3}$ A distance course, in the MOOC (Massive Open Online Course) modality, was developed to provide continuing dental education to assist dental surgeons in managing patients with chronic diseases.

The free course addressed three epidemiologically important pathologies: diabetes, hypertension and chronic kidney disease. Provided in two editions from 2016 to 2018, the course had 13,089 participants. The purpose of this study is to investigate the feminisation of dentistry by examining 
the profile of the participants of certified MOOC courses for dentists offered nationally by distance learning.

\section{Methods}

This is a cross-sectional, descriptive study conducted with the collection of secondary data from different sources. Data of dentists were obtained from the databases of the Federal Council of Dentistry ${ }^{4}$ and National Registry of Health Facilities $^{5}$ (CNES) database. Data of dentistry courses were obtained from the National Institute for Educational Studies and Research Anísio Teixeira (INEP) ${ }^{6}$ higher education data and Registry of Higher Education Institutions and Courses (e-MEC). ${ }^{7}$ Data of the MOOC course were collected in the Arouca Platform. ${ }^{3}$ Descriptive statistics are used for the data presentation.

The study was approved by the research ethics committees of the School of Dentistry, University of São Paulo (no. 2.201.772). This investigation was conducted according to the Declaration of Helsinki.

\section{Results}

The first two Dentistry courses in Brazil were offered in $1884 .^{8}$ After a little more than 130 years, Brazil has the largest number of university courses in dentistry, with 331 courses providing 40,077 openings every year ${ }^{6,7}$ and consequently, it has the largest number of dentists worldwide (268,512), according to the Federal Council of Dentistry, the institution responsible for supervising the professional practice in the country. ${ }^{4}$ Over the last 50 years there has been a steady increase in the number of female dentists in practice such that $54.9 \%$ of dentists are now female (Figure 1). ${ }^{4}$

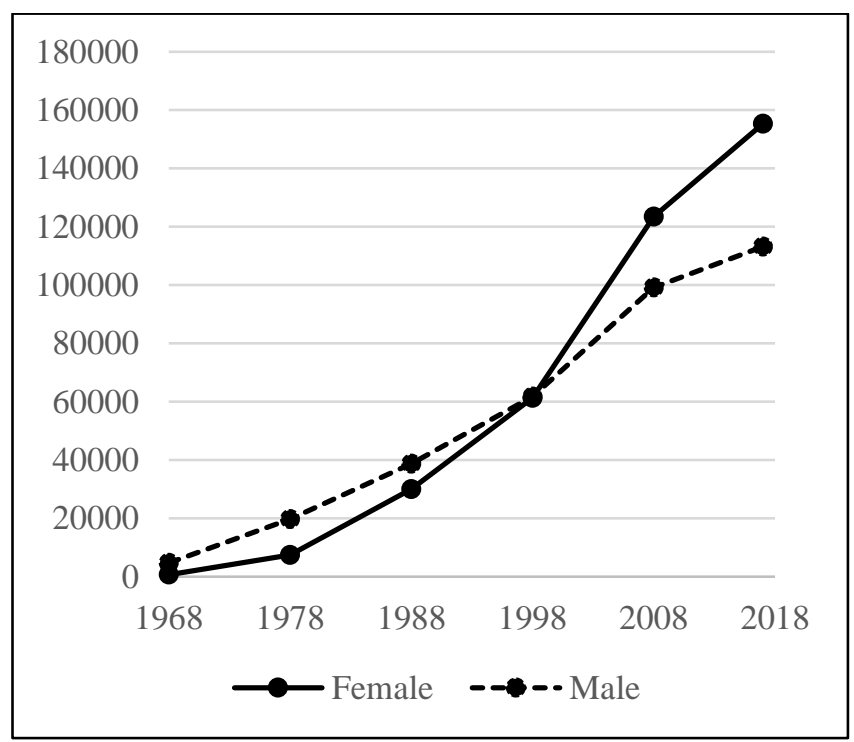

Figure 1. Brazilian dentists by gender from 1968 to 2017.

There are also progressively more females in dental specialties with a female prevalence in paediatric dentistry
(87\%), restorative dentistry $(66 \%)$, endodontic $(64 \%)$, orthodontic $(58 \%)$ and periodontic $(54 \%)$ specialties. They are however a minority in the surgery (22\%) and dental Implant $(28 \%)$ specialties. ${ }^{4}$ Compared to other countries, there are more female dentists in Brazil than males. ${ }^{4,8,9}$

The profile of participants in the MOOC course, Dentistry for Patients with Chronic Diseases (DPCD), followed the same trend of feminisation. Of the 13,089 participants, $73.7 \%$ of those enrolled in the first edition and $73.6 \%$ in the second edition were female dentists reflecting the feminisation of Dentistry in Brazil. Enrolled participants, male and female came from 1,752 of the country's 5,570 municipalities $(31.5 \%)$. The course, which is free, was divided into three units, requiring 45 hour of study to complete the modules and addressed issues about the dental care of patients with diabetes, chronic kidney disease and hypertension (Figure 2).

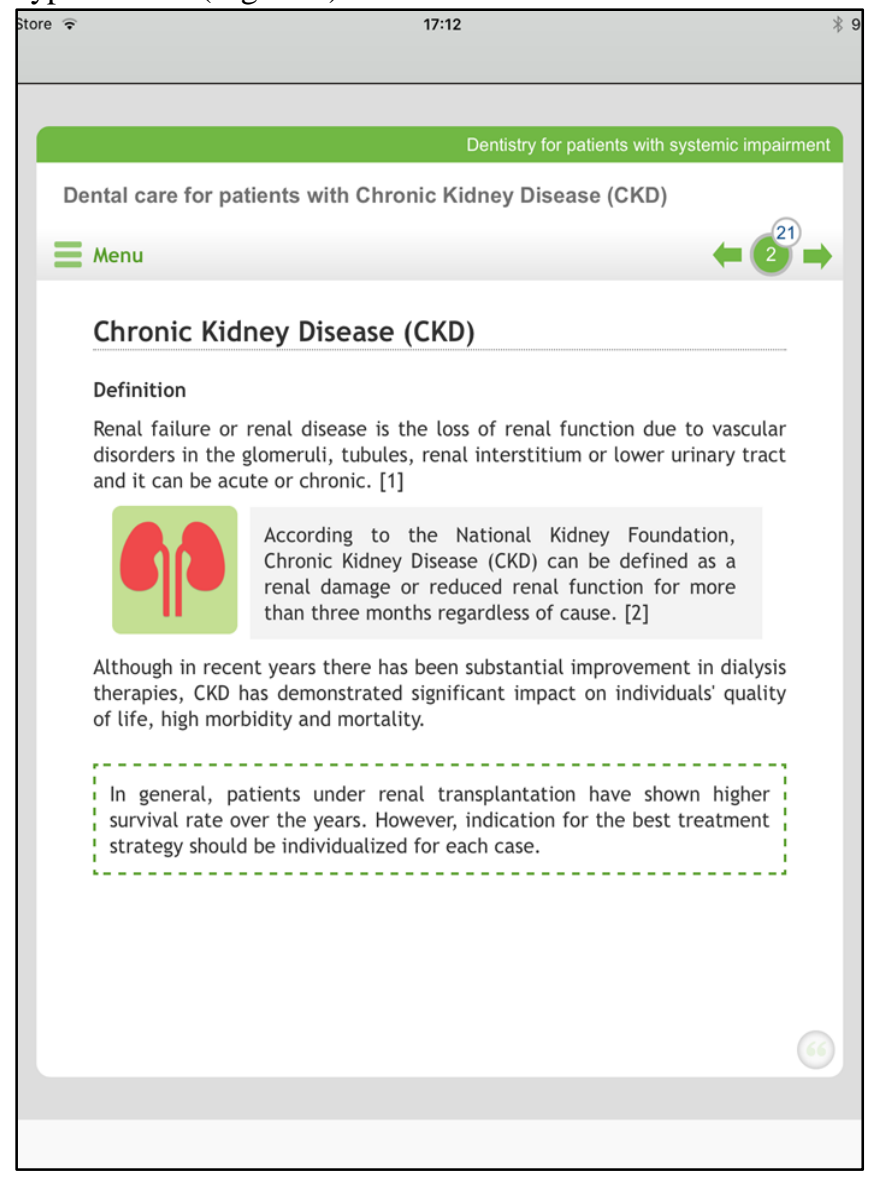

Figure 2. Illustrative image of the English version e-book.

Certification of satisfactory completion of the course was granted if the student correctly answered, at least $70 \%$ of the 10 questions in a multiple-choice questionnaire. The course was completed by $30 \%$ of all individuals in the first edition and $28 \%$ in the second one. The course content is still made available in free mobile applications in Google Play and Apple Store. 


\section{Discussion}

By incorporating the currently available technological resources, the Brazilian public healthcare system SUS provides continuing education to thousands of healthcare professionals spread throughout the country, by means of MOOC-type distance courses. More than 1,500,000 healthcare workers have already participated in continuing education and qualification courses through the UNA-SUS system distance learning. ${ }^{2}$ The MOOCs are developed by Brazilian public universities in partnership with UNA-SUS. The high Internet penetration in Brazil (67\% of the population had access to Internet in 2017) and use of Mobile phones to access Internet $(71 \%)^{10}$ have allowed dissemination of knowledge to professionals living in distant areas and without access to more specialised education. Probably these factors explain the success of DPCD course. The predominantly female profile of the individuals enrolled in MOOC Dentistry for Patients with Chronic Diseases reflects the growing prevalence of women in dentistry in Brazil. This is due in part to the growing inclusion of women in education from the elementary levels to university, and subsequently in specialisation and postgraduate courses, since the 1980s. ${ }^{8}$ In addition, more women complete high school and enter higher education than men. ${ }^{6,7}$

Despite female prevalence in Dentistry, males predominate in some specialties, such as surgery. This may affect the provision of specialised dental services in the medium and long term. Likewise, although the number of dentists has increased over the time, the geographical distribution of professionals is uneven, with most of the professionals concentrated in the Southeast region.

Limitations of this study such as the use of secondary data must be considered, as the secondary databases may be incomplete and may need to be updated and continuously maintained to be considered as reliable.

\section{Conclusion}

The MOOC for dentistry for patients with chronic diseases shows a picture of the feminisation of dentistry which has occurred in the last 20 years. A phenomenon that is similar to that of other countries, it needs to be better investigated in Brazil, so that public policies such as the qualification of healthcare professionals by means of distance education, may take the profession's feminisation into consideration.

\section{Corresponding author:}

Deise Garrido

Department of Orthodontics and Paediatric Dentistry

School of Dentistry of the University of São Paulo

São Paulo, SP, BrazilBrazil

E-mail: deisegarrido@usp.br
Conflict of interest. The authors declare no conflicts of interest.

Acknowledgments. This study was supported by a $\mathrm{PhD}$ fellowship from the Fundação Coordenação de Aperfeiçoamento de Pessoal de Nível Superior (CAPES) (proc 1581358) to the author (DG). The funder had no role in study design, data collection and analysis, decision to publish or preparation of the manuscript.

\section{References}

1. Brazil. Ministry of Health. Datasus. National Registry of Health Facilities. (2018). Available at:

http://cnes.datasus.gov.br/pages/consultas.jsp accessed 13 August 2018.

2. Brazil. Ministry of Health. UNA-SUS Brazilian Healthcare System's Open University. (2018). Available at: https://www.unasus.gov.br accessed 10 August 2018.

3. Brazil. Ministry of Health. SUS' Open University. Arouca Platform. (2018). Available at: https://www.unasus.gov.br/numeros/arouca accessed 13 August 2018. https://doi.org/10.1111/eje.12386

4. Federal Council of Dentistry. Federal Council of Dentistry. (2018). Available at:

http://cfo.org.br/website/estatisticas/quantidade-geralde-cirurgioes-dentistas-especialistas/ accessed 13 August 2018.

5. Brazil. Ministry of Health. Datasus. National Registry of Health Facilities. (2018). Available at:

http://cnes.datasus.gov.br/pages/consultas.jsp accessed 13 August 2018.

6. Brazil. Ministry of Education. National Institute for Educational Studies and Research Anísio Teixeira. (2018). Available at: http://portal.inep.gov.br/web/guest/educacao-superior accessed 13 August 2018.

7. Brazil. Ministry of Education. e-MEC Registry of Higher Education Institutions and Courses. (2018). Available at: http://emec.mec.gov.br accessed 13 August 2018.

8. Morita MC, Haddad AE, Araújo ME. Perfil Atual e Tendências do Cirurgião Dentista Brasileiro. In Perfil Atual e Tendências do Cirurgião Dentista Brasileiro, 2010.

9. Furtinger VB, Alyeva R, Maximovskaya LN. Postaje li europska stomatologija žensko zanimanje ? Is European Dentistry Becoming a Female Profession? Acta Stomatol Croat [Internet]. 2013;47(1):51-7.

Available at: http://www.ascro.hr/fileadmin/user_upload/2013/numb er_2013-1/barac_furtinger_20131/barac_furtinger_2013-1.pdf accessed 19 February 2019. 
10. Brazilian Internet Steering Committee (CGI.br). Survey on the use of information and communication technologies in Brazilian households: ICT households 2017 [Internet]. São Paulo; 2016. Available at:

https://www.cetic.br/media/docs/publicacoes/2/tic_do m_2017_livro_eletronico.pdf accessed 16 February 2019. 